\title{
Efeitos da Suplementação Alimentar com Whey Protein e Leucina em Ratos Normais
}

\section{Effects of Dietary Supplementation with Whey Protein and Leucine in Normal Mice}

\author{
Alessandro Carvalho Alves dos Santos ${ }^{\mathrm{a} *}$; Maria do Carmo de Carvalho e Martins ${ }^{\mathrm{bc}}$; Lorayne de Araújo Costa Pereira ${ }^{\mathrm{c}}$; \\ Nicholas dos Santos Barros ${ }^{c}$; Moisés Lopes Carvalho ${ }^{c}$
}

${ }^{a}$ Faculdade Santo Agostinho, Pós-Graduação Lato Sensu em Nutrição Clínica, PI, Brasil

bUniversidade Federal do Piauí, Programa de Pós-Graduação Stricto Sensu em Alimentos e Nutrição, PI, Brasil

${ }^{\mathrm{c} C e n t r o ~ U n i v e r s i t a ́ r i o ~ U N I N O V A F A P I, ~ C u r s o ~ d e ~ M e d i c i n a, ~ P I, ~ B r a s i l ~}$

*E-mail: alessandrocarvalho02@hotmail.com

Recebido: 11 de abril de 2015; Aceito: 10 de setembro de 2015

\begin{abstract}
Resumo
$\mathrm{O}$ uso indiscriminado de suplementos proteicos e à base de aminoácidos tem despertado o interesse em avaliar possíveis efeitos prejudiciais à saúde associados à ingestão de doses excessivas, especialmente sobre a função renal. O objetivo foi avaliar o efeito da suplementação alimentar com whey protein e leucina sobre a função renal, parâmetros metabólicos e massa corporal de ratos sob condições fisiológicas. Rattus norvegicus, pesando $327 \pm 24 \mathrm{~g}$ foram distribuídos em cinco grupos ( $\mathrm{n}=5-7 /$ grupo) e alimentados com ração comercial e água ad libitum e tratados v.o com whey protein nas doses de 0,45 e $1,8 \mathrm{~g} / \mathrm{kg} / \mathrm{dia}$ (WP1 e WP2), leucina 0,675 e 1,35 g/ $\mathrm{kg} / \mathrm{dia}$ (LEU1 e LEU2), ou água (controle C). A suplementação foi feita por gavagem, diluindo-se os suplementos em água destilada em volume de $10 \mathrm{~mL} / \mathrm{kg}$. Após quatro semanas, amostras de sangue foram obtidas e processadas para dosagens bioquímicas de creatinina, ureia, triglicérides, colesterol total e frações e glicemia de jejum. Para avaliação estatística, utilizou-se ANOVA seguida de pós-teste Tukey, com nível de significância de 5\%. Houve ganho de peso em WP2 e LEU2 e menor consumo alimentar em WP1, WP2 e LEU1. Não houve aumento dos níveis de creatinina e ureia plasmática, indicativos de disfunção renal. Foi observada redução estatisticamente significativa de triglicérides, colesterol total e glicemia de jejum em LEU1 quando comparado ao controle, $\mathrm{p}<0,05$. Não houve interferência dos tratamentos sobre as frações LDL-c e HDL-c. A suplementação alimentar com whey protein e leucina não resultou em danos renais. A leucina na dose de $0,675 \mathrm{~g} / \mathrm{Kg}$ promoveu melhor perfil metabólico.
\end{abstract}

Palavras-chave: Suplementos Nutricionais. Proteínas do Leite. Leucina.

\begin{abstract}
The indiscriminate use of protein supplements and amino acid base has aroused the interest in evaluating possible detrimental health effects associated with the ingestion of excessive doses, especially on renal function. The objective of the present study was to evaluate the effect of dietary supplementation with whey protein and leucine on renal function, metabolic parameters and body mass of mice under physiological conditions. Rattus norvegicus, weighing $327 \pm 24 \mathrm{~g}$ were divided into five groups ( $n=5-7$ / group) and fed with commercial feed and water ad libitum and whey protein at doses of 0.45 and $1.8 \mathrm{~g} / \mathrm{kg} /$ day (WP1 and WP2), leucine 0.675 and $1.35 \mathrm{~g} / \mathrm{kg} /$ day (Leu1 and LEU2) or water (control C). The supplement was provided by gavage, diluting supplements in distilled water at a concentration of $10 \mathrm{ml} / \mathrm{kg}$. After four weeks, blood samples were obtained and analyzed for biochemical levels of creatinine, urea, triglycerides, total cholesterol and fractions and fasting glucose. For statistical analysis, ANOVA followed by Tukey post-test at 5\% significance level was used. There was weight gain in WP2 and LEU2 and lower food consumption in WP1,WP2 and Leu1. There was no increase in creatinine and urea plasma levels, indicative of renal dysfunction. There was a statistically significant reduction of triglycerides, total cholesterol, and fasting glucose in Leu1 when compared to the control, $p<0.05$. There was no interference of treatment on $L D L-C$ and $H D L-C$ fractions. Supplementing with whey protein and leucine did not result in kidney damage. Leucine at a dose of $0.675 \mathrm{~g} / \mathrm{kg}$ led to improved metabolic profile.
\end{abstract}

Abstract

Keywords: Dietary Supplements. Milk Proteins. Leucine.

\section{Introdução}

O consumo de suplementos proteicos e à base de aminoácidos é feito de forma exarcebada ${ }^{1,2}$. Tal consumo é motivado pela busca de recursos que possam auxiliar a promover ganho de massa magra e redução de gordura corporal, e para isso os atletas tendem a ingerir altas doses de suplementos proteicos sem conhecer seus possíveis danos à saúde ${ }^{3,4}$. Ademais, o consumo excessivo de proteínas, na ausência de maiores requerimentos proteicos não é recomendado pela literatura ${ }^{5-7}$.

As proteínas do soro do leite ou whey protein são alvo de estudos que têm como finalidade verificar a relação entre suplementação de forma demasiada e possíveis prejuízos no funcionamento renal, tanto em modelos experimentais com animais submetidos a treinamento físico, quanto com animais sob condições fisiológicas ${ }^{6-9}$. A creatinina plasmática é um dos marcadores bioquímicos de função renal, e níveis elevados indicam disfunção renal ${ }^{10}$.

Neste contexto, um estudo avaliou o efeito da suplementação com whey protein em ratos sob condições fisiológicas, submetidos ao exercício físico, e foi verificado aumento da creatinina plasmática após oito semanas de suplementação por gavagem oral, evidenciando que o excesso de proteínas em animais sob condições fisiológicas causou sobrecarga renal e lesão hepática9 . 
Por outro lado, benefícios relacionados ao consumo de proteínas do soro do leite foram demonstrados em estudos que abordaram o uso de whey protein como ferramenta para o controle e prevenção de fatores de risco para doenças endocrinometabólicas em seres humanos. As doses usadas variaram de cinco a $54 \mathrm{~g} /$ dia em períodos de até doze semanas, e não foram verificados danos sobre a função renal ${ }^{11}$. A whey protein melhorou o perfil lipídico e promoveu redução de glicemia pós-prandial em ratos sob condições fisiológicas ${ }^{12} \mathrm{e}$ em indivíduos portadores de diabetes mellitus tipo II $^{12-14}$.

A redução do consumo alimentar é tida como um dos efeitos fisiológicos positivos das proteínas do soro do leite sobre o controle de taxas metabólicas. Tal efeito é explicado em parte, pela potencial ação dos peptídeos e aminoácidos destas proteínas sobre a liberação de hormônios intestinais que regulam a saciedade ${ }^{11,15}$. Assim, essa ação poderia ser aplicada como ferramenta no tratamento e prevenção de doenças endocrinometabólicas ${ }^{16}$. Estudos que estabeleçam doses seguras de suplementação com whey protein em indivíduos saudáveis para que se possa usufruir de suas propriedades funcionais, portanto, são necessários ${ }^{9}$.

Os aminoácidos de cadeia ramificada - AACR: leucina, valina e isoleucina, são essenciais na dieta humana, com destaque para a leucina, que apresenta diferentes propriedades fisiológicas ${ }^{17}$. A leucina pode ser encontrada em grandes concentrações $(11,8 \mathrm{mg} / 100 \mathrm{~g})$ na constituição das proteínas do soro do leite ${ }^{18}$, sendo considerada promissora em terapia antiatrófica, pois reduz a proteólise em estado fisiológico ${ }^{19-21}$.

A leucina apresenta potencial terapêutico relacionado com a homeostase glicêmica e controle da massa corporal ${ }^{22-26}$, devido a sua ação na saciedade e no aumento do gasto energético e, dessa forma, poderia ser utilizada como recurso auxiliar no tratamento de doenças metabólicas, porém devem ser estabelecidas as doses exatas e o tempo de suplementação para resultados satisfatórios ${ }^{27}$. O aumento de AACR na corrente sanguínea pela ingestão de doses elevadas em longo prazo pode correlacionar-se com aumento da resistência à insulina e posterior desenvolvimento de diabetes ${ }^{28,29}$.

Embora diversos estudos utilizando modelos experimentais tenham associado o consumo de proteínas do soro do leite ou leucina com a intensificação das adaptações fisiológicas decorrentes do treinamento físico de resistência, incluindo aumento da síntese de proteínas com ganho de massa magra $^{19,30,31}$, bem como seus efeitos sobre o metabolismo de lipídeos e prevenção de doenças metabólicas ${ }^{32,33}$, poucos estudos verificaram seus efeitos sobrea função renal e parâmetros metabólicos em estado fisiológico ${ }^{7,12}$.

Desta forma, o objetivo deste estudo foi avaliar os efeitos da suplementação alimentar com whey protein e leucina sobre a função renal, perfil metabólico e massa corporal em ratos.

\section{Material e Métodos}

Foram utilizados 28 ratos machos da linhagem Wistar (Rattus norvergicus, variedade albinus) com idade de 90 dias e com massa corporal inicial média de $327 \pm 24 \mathrm{~g}$, provenientes do biotério do Centro Universitário UNINOVAFAPI, mantidos em gaiolas coletivas sob condições padrão de iluminação (ciclo claro/escuro de 12horas), temperatura (22 \pm $\left.1{ }^{\circ} \mathrm{C}\right)$ e umidade $(65 \%)$.

Os animais foram distribuídos em cinco grupos $(n=5$ 7/grupo), de acordo com a massa corporal para que se mantivessem as mesmas médias para cada grupo e tratados v.o durante quatro semanas com whey protein concentrada comercial $^{\circledR}$ nas doses de $0,45 \mathrm{~g} / \mathrm{kg} / \mathrm{dia}(\mathrm{WP} 1, \mathrm{n}=5)$ e $1,8 \mathrm{~g} / \mathrm{kg} /$ dia (WP2, n=5) ou leucina $0,675 \mathrm{~g} / \mathrm{kg} / \mathrm{dia}(\mathrm{LEU} 1, \mathrm{n}=6)$ e 1,35 $\mathrm{g} / \mathrm{kg} / \mathrm{dia}$ (LEU2, $\mathrm{n}=5$ ) ou água (Controle $-\mathrm{C}, \mathrm{n}=7$ ). A amostra de animais foi feita por conveniência.

As doses de whey protein e leucina foram baseadas em estudo que tiveram como finalidade verificar os efeitos desse tipo de suplementação sobre parâmetros metabólicos e sobre a função renal ${ }^{8,9}$. Durante o período experimento os animais foram mantidos com ração comercial Labina Purina ${ }^{\circledR}$ e água $a d$ libitum. A administração foi feita por gavagem com diluição de whey protein e leucina em água destilada em volume de $10 \mathrm{~mL} / \mathrm{kg}$ de massa corporal segundo Toedbusch et al. ${ }^{8}$, uma vez ao dia, no período da manhã, sempre no mesmo horário, de forma semelhante ao descrito no estudo de Nunes et al. ${ }^{9}$.

O consumo alimentar foi determinado pela diferença entre quantidade de ração colocada no comedouro e a quantidade restante 24 horas depois. A massa corporal foi medida duas vezes por semana utilizando-se balança tríplice escala. Ao final do período de tratamento, os animais foram mantidos em jejum de 12 horas e eutanasiados com sobredose de tiopental sódico $(100 \mathrm{mg} / \mathrm{kg})$ por via intraperitoneal. As amostras de sangue foram obtidas por punção da veia cava inferior e processadas para obtenção do soro sanguíneo para determinações bioquímicas.

A função renal foi avaliada pelos biomarcadores creatinina e ureia plasmática, por meio de ensaio cinético de dois pontos. O perfil lipídico foi avaliado pela quantificação de triglicérides, colesterol total e frações em sistema enzimático de ponto final. A glicose plasmática foi obtida pelo método de ponto final. As dosagens foram feitas utilizando reagentes de kits comerciais (Labtest Diagnóstica SA, Lagoa Santa-MG, Brasil), o processo das análises e os resultados foram obtidos com auxílio de equipamento semi-automatizado (Labmax pleno ${ }^{\circledR}$ ).

As análises estatísticas foram realizadas utilizando o programa GraphPadPrism ${ }^{\circledR}$ (versão 3.04, GraphPad Software). Os dados foram expressos em média e desvio padrão da média (DPM). Para comparação de médias das variáveis estudadas entre os grupos utilizou-se ANOVA seguida de pós-teste de Tukey. O nível de significância foi estabelecido em $\mathrm{p}<0,05$.

O trabalho foi aprovado pela Comissão de Ética no Uso de Animais do Centro Universitário UNINOVAFAPI (CEUA/ UNINOVAFAPI), parecer 008/2014. O estudo foi conduzido de acordo com os princípios éticos em experimentação do Conselho Nacional de Experimentação Animal - CONCEA. 


\section{Resultados e Discussão}

\subsection{Efeito da suplementação com whey protein e leucina sobre a massa corporal e consumo alimenta}

$\mathrm{O}$ efeito do tratamento com whey protein sobre a massa corporal e consumo alimentar dos animais é evidenciado na Tabela 1. Os animais suplementados com whey protein (WP2) apresentaram, ao final do tratamento, massa corporal significativamente maior $(\mathrm{p}<0,001)$ em relação ao controle. O consumo alimentar foi significativamente menor $(p<0,001)$ em relação ao grupo controle para os dois tratamentos, WP1 e WP2.

Tabela 1: Massa corporal inicial e final médio e consumo alimentar diário $(\mathrm{g} / 24 \mathrm{~h})$ de ratos tratados com whey protein 0,45 (WP1) ou 1,8 g/kg/dia (WP2) v.o. durante quatro semanas. Teresina (PI), 2014

\begin{tabular}{llcc}
\hline \multirow{2}{*}{ Grupos } & \multicolumn{2}{c}{ Massa corporal média (g) } & Consumo médio diário (g/24) \\
\cline { 2 - 4 } & Massa Inicial & Massa Final & Consumo Alimentar \\
\hline Controle & $326,91 \pm 2,02^{\mathrm{a}}$ & $319,92 \pm 4,23^{\mathrm{a}}$ & $16,03 \pm 0,23$ \\
WP1 & $326,82 \pm 3,28^{\mathrm{a}}$ & $328,39 \pm 4,28^{\mathrm{a}}$ & $14,75 \pm 1,18^{*}$ \\
WP2 & $327,49 \pm 9,39^{\mathrm{a}}$ & $342,50 \pm 7,50^{\mathrm{b}^{\mathrm{a}}}$ & $14,50 \pm 2,16^{*}$ \\
\hline
\end{tabular}

Valores expressos em média (M) e \pm desvio padrão da média (DPM); $\mathrm{n}=5-7 /$ grupo. C: ratos com água $(10 \mathrm{~mL} / \mathrm{kg})$. Letras diferentes no sentido vertical indicam diferenças significativas para a massa corporal inicial e final e $(*)$ indica diferença em relação ao grupo controle. * Efeito do tratamento sobre o consumo alimentar em relação ao grupo controle, p $<0,001$.

Fonte: Dados da pesquisa.

Como observado na Tabela 1, o grupo WP1 reduziu o consumo alimentar dos animais quando comparado ao controle $(\mathrm{p}<0,001)$, entretanto não foram observadas mudanças na massa corporal. A redução do consumo alimentar, em outros estudos que utilizaram proteinas do soro do leite, auxiliou a reduzir a massa corporal ${ }^{34,38}$.

O grupo WP2 obteve aumento de massa corporal ao final do tratamento, mesmo havendo redução do consumo alimentar. Para alguns autores, o mais provável é que o excesso de proteínas seja utilizado como fonte de energia ou armazenada como gordura corporal $1^{5,19}$.

Os resultados aqui encontrados divergem com os achados de Freudenberg et al. ${ }^{34}$ em que foi observado redução de massa corporal em decorrência do aumento da saciedade em ratos que consumiram ração elaborada com 50\% de whey protein durante uma semana. Outros autores não encontraram diferenças estatísticas significativas sobre a massa corporal em animais suplementados ou adição de whey protein em substituição a caseína e proteína da soja ${ }^{35-37}$.

Estudos randomizados realizados com seres humanos mostram resultados divergentes. Frestedt et al. ${ }^{38}$ constatou redução de massa corporal em indivíduos saudáveis com restrição energética durante doze semanas, entretanto no estudo conduzido por Pall e Ellis ${ }^{39}$ com mulheres e homens obesos que receberam suplementação de whey protein $(27 \mathrm{~g}$ diluídos em $250 \mathrm{~mL}$ de água, duas vezes ao dia), sem redução efetiva de massa corporal após doze semanas.

Os efeitos de proteínas do soro do leite sobre a redução da massa corporal e saciedade podem ser explicados pela liberação de hormônios anorexígenos, como a leptina, o GLP1(peptídeo semelhante ao glucagon) e a CCK (colecistocinina), e redução de grelina (hormônio orexígeno $)^{4,11,15}$. A liberação de hormônios anorexígenos favorece a redução de massa corporal e da ingestão energética ${ }^{40}$. O glicomacropeptídeo, um dos peptídeos da whey protein, favorece a redução do consumo alimentar por este ser secretagogo da $\mathrm{CCK}^{41,42}$.

Dessa forma, a redução do consumo alimentar nos grupos WP1 e WP2 pode ser explicada pelos efeitos dos peptídeos das proteinas do soro do leite sobre a liberação de hormônios que regulam a saciedade.

O efeito do tratamento com leucina sobre a massa corporal e consumo alimentar é evidenciado na Tabela 2. O grupo LEU2 apresentou, ao final do tratamento, massa corporal significativamente maior em relação ao grupo controle $(p<0,001)$, entretanto não foram observadas alterações no consumo alimentar $(p>0,05)$. Houve redução significativa do consumo alimentar para o grupo LEU1 em relação ao grupo controle e em relação ao grupo LEU2, p<0,001.

Tabela 2: Massa corporal inicial e final médio e consumo alimentar diário $(\mathrm{g} / 24 \mathrm{~h})$ de ratos tratados com leucina 0,675 (LEU1) e 1,35 g/kg/dia (LEU2) v.o. durante quatro semanas. Teresina (PI), 2014

\begin{tabular}{lccc}
\hline \multirow{2}{*}{ Grupos } & \multicolumn{2}{c}{ Massa corporal média (g) } & Consumo médio diário (g/24h) \\
\cline { 2 - 4 } & Massa inicial & Massa final & Consumo alimentar \\
\hline Controle & $326,91 \pm 2,02^{\mathrm{a}}$ & $319,92 \pm 4,23^{\mathrm{a}}$ & $16,03 \pm 0,23$ \\
LEU1 & $328,35 \pm 6,36^{\mathrm{a}}$ & $331,63 \pm 5,13^{\mathrm{a}}$ & $14,48 \pm 1,94^{* *}$ \\
LEU2 & $326,64 \pm 8,53^{\mathrm{a}}$ & $344,22 \pm 9,20^{\mathrm{b}^{*}}$ & $16,08 \pm 2,89$ \\
\hline
\end{tabular}

Valores expressos em média (M) e \pm desvio padrão da média (DPM); $n=5-7 /$ grupo. C: ratos com água (10 mL/ $\mathrm{kg})$. Letras diferentes no sentido vertical indicam diferenças significativas para massa corporal inicial e final e $(*)$ indica diferença em relação ao grupo controle ** Efeito do tratamento sobre o consumo alimentar em relação ao grupo controle e LEU2, $\mathrm{p}<0,001$.

Fonte: Dados da pesquisa. 
A leucina é estudada pelos seus efeitos na modulação da homeostase glicêmica e na sensibilidade à insulina, podendo exercer dessa forma, efeitos sobre a manutenção da massa corporal $^{27}$. Estudos in vitro e in vivo mostraram seus efeitos no aumento do gasto energético e da saciedade, podendo ser efetiva no controle da massa corporal ${ }^{27}$.

Os resultados obtidos para a dose de $0,675 \mathrm{~g} / \mathrm{kg} / \mathrm{dia}$ de leucina (LEU1) mostraram-se satisfatórios, pois não houve alterações de massa corporal e houve redução do consumo alimentar durante o tratamento.

Um estudo mostrou aumento da massa corporal em ratos com ração acrescida de $4,5 \%$ de leucina após vinte e quatro semanas ${ }^{42}$. Porém, o acréscimo de $1,6 \%$ de leucina não alterou este parâmetro em ratos, em modelo de resistência à insulina, após quatro semanas ${ }^{35}$. Alterações de massa corporal não foram observadas em animais que receberam dietas com teor adequado de proteínas (20\% de proteínas) ou em dieta (AIN 93) contendo $50 \%$ de whey protein acrescidas com a mesma quantidade de leucina durante quatorze semanas ${ }^{43,44}$.

A dose de 1,35 g/kg/dia de leucina durante dez dias não alterou a massa corporal nos animais suplementados em relação ao controle ${ }^{45}$. Essa dose é igual àquela utilizada no tratamento do grupo LEU2 deste estudo e as diferenças nos resultados obtidos poderiam ser relacionadas com a maior duração do tratamento. Como citado acima, o tempo de administração e a dose de leucina parece exercer diferentes efeitos sobre a massa corporal.

Quanto ao efeito da leucina no consumo alimentar, o resultado para o grupo que recebeu dose de $1,35 \mathrm{~g} / \mathrm{kg} /$ dia (LEU2), quando comparado ao grupo controle, está em concordância com estudo que investigou o efeito da leucina no controle da saciedade, onde a leucina em água para beber na concentração de $17 \mathrm{~g} / \mathrm{L}$ ou dose de $10 \mathrm{mg} /$ dia, por gavagem oral, não surtiu efeito sobre a saciedade, enquanto a dose de $1,1 \mu \mathrm{g}$, diretamente no ventrículo lateral promoveu aumento de hormônios anorexígenos ${ }^{46}$. Ressalta-se que mais estudos são necessários, considerando que o tratamento dietético com a dose de $0,675 \mathrm{~g} / \mathrm{kg}$ de leucina resultou em redução do consumo alimentar em relação ao controle e ao grupo LEU2, tal fato pode ser atribuído a eficácia desta dose sobre o aumento da saciedade.

\subsection{Efeito da suplementação com whey protein e leucina sobre função renal}

Não foram encontradas diferenças estatisticamente significativas entre os grupos tratados e o grupo controle para os níveis séricos de creatinina e ureia, indicando que não houve prejuízo sobre a função renal (Figura 1).

Figura 1: Creatinina sérica (A) e ureia (B) de animais tratados com whey protein 0,45 (WP1) ou $1,8 \mathrm{~g} / \mathrm{kg} / \mathrm{dia}$ (WP2) ou leucina 0,675 (LEU1) e 1,35 g/kg/dia (LEU2) v.o. durante quatro semanas

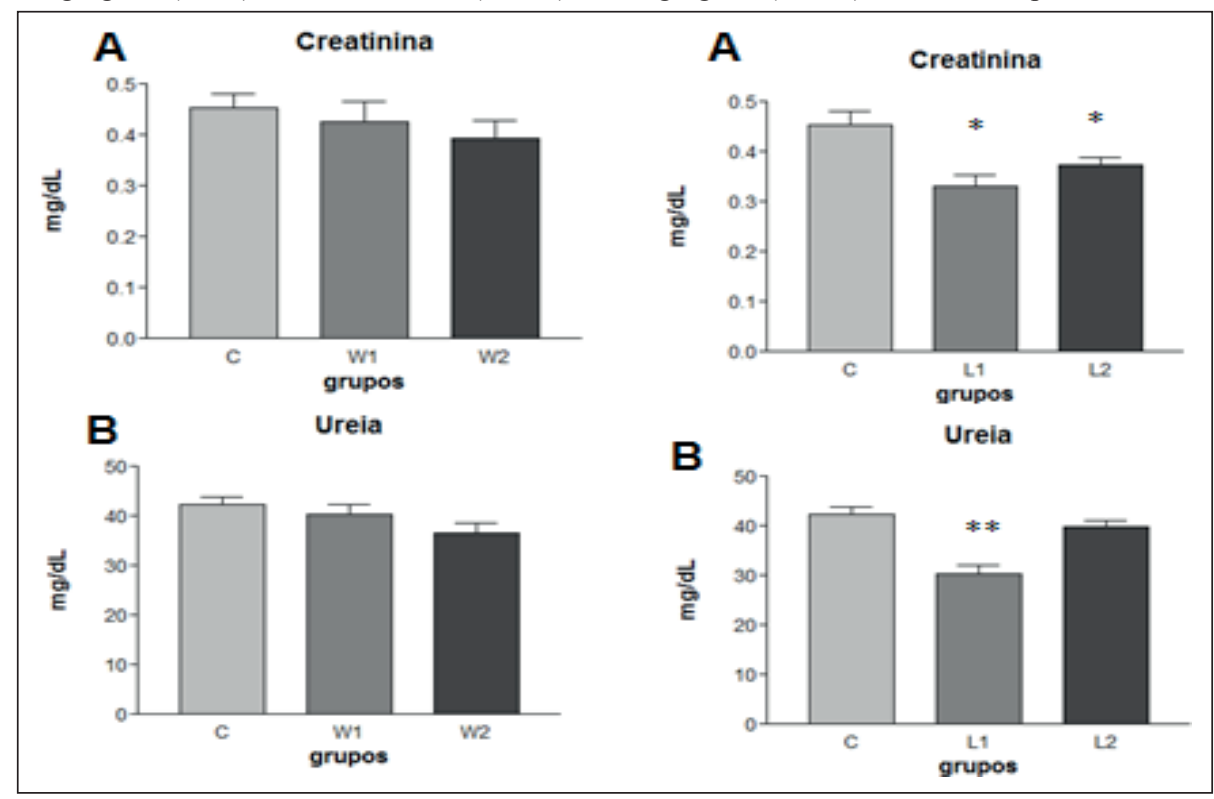

${ }^{*} \mathrm{p}<0,05$ em relação ao controle, ${ }^{* *} \mathrm{p}<0,05$ em relação ao grupo controle e LEU2.

Fonte: Dados da pesquisa.

Por outro lado, estudo em que ratos em condições fisiológicas que receberam $1,8 \mathrm{~g} / \mathrm{kg} / \mathrm{dia}$ de whey protein $\mathrm{em}$ relação aos submetidos ao treinamento físico recebendo a mesma dose durante oito semanas demonstrou níveis de creatinina elevados, apontando prejuízo sobre a função renal em animais não exercitados ${ }^{9}$.
Os efeitos potencialmente nocivos de dietas hiperproteicas sobre a função renal são associados a um "excesso de trabalho renal", este pode elevar a taxa de filtração glomerular - TFG e induzir hiperfiltração glomerular e promover alterações no funcionamento e na morfologia renal $1^{47,49}$. 
Aparacio et al. ${ }^{7}$ avaliaram os efeitos de dietas hiperproteicas (AIN 93 com 45\% de proteínas de soja) sobre parâmetros morfológicos e biomarcadores de função renal plasmáticos em ratos durante doze semanas e concluíram que em longo prazo tais dietas podem comprometer a saúde renal.

\subsection{Efeito da suplementação com whey protein e leucina sobre perfil lipídico}

O perfil sérico de lipídeos dos animais após quatro semanas com whey protein e leucina é mostrado na Tabela 3 .

Tabela 3: Níveis séricos de triglicerídeos (mg/dL), colesterol total (mg/dL), colesterol HDL (mg/dL) e colesterol LDL (mg/dL) de ratos tratados com whey protein 0,45 (WP1) e 1,8 g/kg/dia (WP2) ou leucina 0,675 (LEU1) e 1,35 g/kg/dia (LEU2) v.o. após quatro semanas

\begin{tabular}{lcccc}
\hline \multicolumn{1}{c}{ Grupos } & Triglicerídeos $(\mathbf{m g} / \mathbf{d L})$ & Colesterol total $(\mathbf{m g} / \mathbf{d L})$ & Colesterol HDL (mg/dL) & Colesterol LDL (mg/dL) \\
\hline Controle & $96,71 \pm 16,12$ & $75,00 \pm 14,94$ & $36,42 \pm 5,25$ & $29,05 \pm 11,73$ \\
Wheyprotein (WP1) & $59,68 \pm 15,96$ & $63,00 \pm 17,98$ & $29,33 \pm 3,14^{*}$ & $25,52 \pm 15,96$ \\
Wheyprotein (WP2) & $58,24 \pm 14,64$ & $68,20 \pm 19,47$ & $28,20 \pm 5,84^{*}$ & $31,25 \pm 13,45$ \\
Leucina (LEU1) & $42,85 \pm 3,52^{*}$ & $44,80 \pm 13,31^{* *}$ & $30,40 \pm 5,12$ & $24,64 \pm 5,50$ \\
Leucina (LEU2) & $71,46 \pm 16,00$ & $80,83 \pm 21,71$ & $28,50 \pm 4,59^{*}$ & $27,22 \pm 5,41$ \\
\hline
\end{tabular}

Valores expressos em média (M) e \pm desvio padrão da média (DPM); $\mathrm{n}=5-7 /$ grupo. C: ratos com água ( $10 \mathrm{~mL} / \mathrm{kg})$. ${ }^{*} \mathrm{p}<0,001 \mathrm{em}$ relação ao controle, **p $<0,001$ em relação ao controle e LEU2.

Fonte: Dados da pesquisa.

O tratamento com whey protein promoveu redução de colesterol total e triglicérides, entretanto esta redução não foi estatisticamente significativa quando comparada ao grupo controle $(p>0,05)$. Para o grupo LEU1, houve redução de forma significativa nos níveis de colesterol total comparados ao controle, $\mathrm{p}<0,05$, e os triglicérides foram reduzidos quando comparados ao controle e ao grupo LEU2. Houve redução nos níveis de HDL-c nos grupos (WP1, WP2 e LEU2) em comparação ao grupo controle $(\mathrm{p}<0,05)$, não houve alterações significativas de LDL-c entre os grupos ( $\mathrm{p}>0,05)$.

Em estudo com ratos alimentados com dieta contendo proteínas do soro do leite em substituição a caseína, não houve redução significativa do colesterol total e triglicérides ${ }^{53}$. O efeito hipocolesterolêmico das proteínas do soro do leite foi verificados no estudo de Teixeira et al. ${ }^{12}$ no qual houve redução estatisticamente significativa de colesterol total e LDL-c e aumento do HDL-c em ratos sob condições fisiológicas que receberam ração padrão com whey protein em substituição a caseína.

Os mecanismos envolvidos na modulação do controle energético e do perfil lipídico promovido pelas proteínas do soro do leite, em animais e seres humanos, ainda não estão elucidados pela literatura ${ }^{46}$. Dentre os fatores que influenciam os efeitos das proteínas do soro sobre o perfil lipídico de ratos, a quantidade de proteína na dieta parece ser um fator essencial $^{53}$.

Mortensen et al. ${ }^{48}$ compararam os efeitos de diferentes fontes de proteínas sobre os níveis séricos de lipídeos após consumo de refeições hiperlipídicas em indivíduos com diabetes tipo 2, sendo que as refeições continham $45 \mathrm{~g}$ de proteínas de diferentes fontes alimentares. Os resultados foram menores níveis de triglicérides naqueles indivíduos que receberam dieta contendo whey protein, entretanto foram não observadas alteração de colesterol total e suas frações.
Contrapondo os resultados para leucina na dose de 0,675 $\mathrm{g} / \mathrm{kg}$ (grupo LEU1) e os achados de Torres-Leal et al. ${ }^{49}$ que também verificaram redução dos níveis plasmáticos de colesterol total, um outro estudo com suplementação de leucina em maior tempo, durante 40 semanas, com acréscimo de $4 \%$ de leucina em ração, resultou em redução de gordura corporal, mas não foram observadas modificações nos níveis de colesterol total, triglicerídeos e glicemia de jejum ${ }^{25}$.

\subsection{Efeito da suplementação com whey protein e leucina sobre a glicemia de jejum}

Para o tratamento com whey protein nas duas doses estudadas, não foram verificadas diferenças estatisticamente significativas sobre a glicemia de jejum, quando comparado ao grupo controle e entre os grupos (WP1 e WP2). O tratamento com leucina na menor dose $(0,675 \mathrm{~g} / \mathrm{kg}$, grupo LEU1) promoveu redução dos níveis de glicose plasmática de jejum em relação ao grupo controle e LEU2 ( $<<0,05)$, o que não foi observado no grupo LEU2. Os resultados para glicose plasmática entre os tratamentos e grupo controle encontramse na Figura 2.

Figura 2: Glicemia de jejum de animais tratados com wheyprotein 0,45 (WP1) ou 1,8 g/kg/dia (WP2) ou leucina 0,675 (LEU1) e $1,35 \mathrm{~g} / \mathrm{kg} / \mathrm{dia}$ (LEU2) v.o. durante quatro semanas

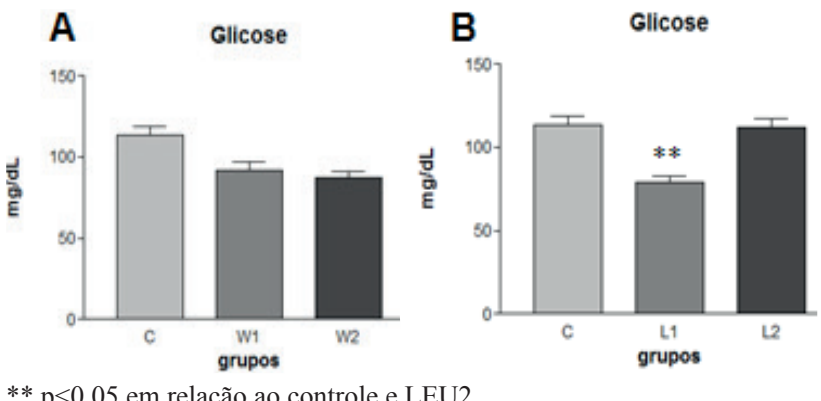

Fonte: Dados da pesquisa. 
O efeito da whey protein na redução de glicose pósprandial é tido pelo aumento de insulina plasmática promovida pela sua composição aminoacídica, em especial pelo aminoácido leucina, que é um secretagogo de insulina ${ }^{51}$. Propriedades insulinotrópicas e hipoglicemiante de whey protein correlacionam-se à liberação de seus peptídeos e aminoácidos durante a sua digestão, atuando na indução de liberação de insulina em indivíduos com diabetes tipo $2^{16}$.

Os resultados aqui encontrados divergem dos achados por Hamad et al. ${ }^{36}$, que verificou menores níveis glicêmicos em ratos com doença hepática não alcoólica induzida após o tratamento de suplementação com whey protein na dose de $0,15 \mathrm{~g} / \mathrm{kg} /$ dia por 28 dias.

Em um estudo randomizado e controlado com dez indivíduos saudáveis que receberam doses de $0,5,10$ e $20 \mathrm{~g}$ de proteínas do soro do leite associadas a $50 \mathrm{~g}$ de carboidratos diluídos em $250 \mathrm{ml}$ de água, duas vezes ao dia, foi verificado uma relação inversamente proporcional dos níveis de glicose capilar com as doses do suplemento protéico ${ }^{52}$.

A leucina não alterou a glicose plasmática em ratos durante uma semana submetidos à dieta hiperlipídica ${ }^{22}$. Efeito semelhante foi observado no estudo de $\mathrm{Adms}^{54}$, que não observou redução da glicose plasmática em ratos alimentados com dietas hiperproteicas ou suplementação de leucina em longo prazo.

\section{Conclusão}

O tratamento de ratos adultos sob condições fisiológicas suplementados com whey protein ou leucina não resultou em alterações nos marcadores bioquímicos de função renal. Os tratamentos com as maiores doses de whey protein $(1,8 \mathrm{~g} / \mathrm{kg}$, grupo WP2) e leucina (1,35 g/kg, grupo LEU2) promoveram aumento de massa corporal ao final do tratamento. Foi observado menor consumo alimentar para os grupos WP1, WP2 e LEU1.

A leucina parece ser promissora na dose de $0,675 \mathrm{~g} / \mathrm{kg} /$ dia em animais sob condições fisiológicas, uma vez que esta dose exerceu efeito positivo sobre a manutenção da massa corporal e promoveu redução do consumo alimentar, além de ter promovido redução dos níveis séricos de triglicérides, colesterol total e glicemia de jejum. Portanto, estudos adicionais devem ser realizados em um maior período de tempo para esta dose para verificação de sua possível ação no aumento da saciedade, controle da massa corporal e de taxas metabólicas e, assim, podendo servir como recurso um nutricional importante para o tratamento e prevenção de doenças metabólicas.

\section{Referências}

1. Nogueira FRS, Souza AA, Brito AF. Prevalência do uso e efeitos de recursos ergogênicos por praticantes de musculação nas academias brasileiras: uma revisão sistematizada. Rev Bras Ativ Fis Saúde 2013;18(1):16-30.

2. Pontes MCF. Uso de suplementos alimentares por praticantes de musculação em academias de João Pessoa-PB. Rev Bras
Nutr Esportiva 2013;7(37):19-27.

3. Alves C, Lima RVB. Uso de suplementos alimentares por adolescentes. J Pediatr 2009;85(4):287-94.

4. Carrilho LH. Benefícios da utilização da proteína do soro de leite whey protein. Rev Bras Nutr Esportiva 2013;7(40):195203.

5. Terada LC, Godoi MR, Silva TCV, Monteiro TL. Efeitos metabólicos da suplementação do Whey protein em praticantes de exercícios com pesos. Rev Bras Nutr Esportiva 2009;3(16):295-304.

6. Wakefield AP, House JD, Ogborn MR, Weiler HA, Aukema HM. A diet with $35 \%$ of energy from protein leads to kidney damage in female Sprague-Dawley rats. Br J Nutr 2011;106(5): 656-63.

7. Aparicio VA, Nebot E, Moral G, Machado-Vílchez M, Porres JM, Sánchez C, et al. High-protein diets and renal status in rats. Nutr Hosp 2013;28(1):232-7.

8. Toedebusch RG, Childs TE, Hamilton SR, Crowley JR, Booth FW, Roberts MD. Postprandial leucine and insulin responses and toxicological effects of a novel whey protein hydrolysatebased supplement in rats. J Int Soc Sports Nutr 2012;9:24.

9. Nunes R, Silva P, Alves J, Stefani G, Petry M, Rhoden C, et al. Effects of resistance training associated with whey protein supplementation on liver and kidney biomarkers in rats. Appl Physiol Nutr Metab 2013;38:1166-9.

10. Rubin C, Nolin TD, Himmelfarb J. Are biomarkers useful for assessing cardiovascular risk in patients with chronic kidney disease? Curr Opin Nephrol Hypertens 2007;16(6):506-51

11. Sousa GTD, Lira FS, Oliveira EP, Oyama LM, Santos RV, Pimentel GD. Dietary whey protein lessens several risk factors for metabolic diseases: a review. Lip Health Disease 2012;11(67):3-9.

12. Teixeira KR, Silva ME, Neves LX, Santos RC, Pedrosa ML, Haraguchi FK. Whey protein Improves HDL/mon-HDL Ratio and Body Weight Gain in Rats Subjectes to the Resistance Exercise. Braz Arch Biol Technol 2012;55(6):943-50.

13. Petyaev IM, Dovgalevsky PY, Klochkov VA, Chalyk NE, Kyle N. Whey protein Lycosome formulation improves vascular functions and plasma lipids with reduction of markers of inflammation and oxidative stress in prehypertension. Sci World J 2012;1-7.

14. Mortensen LS, Hartvigsen ML, Brader LJ, Astrup A, Schrezenmeir J, Holst JJ, et al. Differential effects of protein quality o postprandial lipemia in response to a fat-rich meal in type 2 diabetes: comparison of whey, casein, gluten, and cod protein. Am J Clin Nutr 2009;90:41-8.

15. Bowen J, Noakes M, Clifton PM. Appetite regulatory hormone responses to various dietary proteins differ by body mass index status despite similar reductions in ad libitum energy intake. J Clin Endocrinol Metab 2006;91(8):2913-9.

16. Jakubowicz D, Froy O. Biochemical and metabolic mechanisms by which dietary whey protein may combat obesity and Type 2 diabetes. J Nutr Biochem 2013;24(1):1-5.

17. Gonçalves LA. A suplementação de leucina com relação à massa muscular em humanos. Rev Bras Nutr Esportiva 2013;7(40):212-23.

18. Tang JE, Phillips SM. Maximizing muscle protein anabolism: the role of protein quality. Curr Opin Clin Nutr Metab Care 2009;12(1):66-71.

19. Mata GR, Navarro F. O efeito da suplementação de leucina na síntese protéica muscular. Rev Bras Nutr Esportiva 2009;3(17):367-78. 
20. Glynn EL, Fry CS, Drummond MJ, Timmerman KL, Dhanani $\mathrm{S}$, Volpi E, et al. Excess Leucine Intake Enhances Muscle Anabolic Signaling But Not Protein Anabolism in Young Men and Women. J Nutr 2010;140(11):1970-6.

21. Vianna D, Teodoro GFR, Torres-Leal FL, Tirapegui J. Protein synthesis regutation by leucine. Braz J Pharmaceutical Sci 2010;46(1):25-9.

22. Freudenberg A, Petzke KJ, Klaus S. Comparison of highprotein diets and leucine supplementation in the prevention of metabolic syndrome and related disorders in mice. J Nutr Biochem 2012;23(11):1524-30.

23. Macotela Y, Emanuelli B, Bang AM, Espinoza DO, Boucher J, Beebe K. Dietary leucine-an environmental modifier of insulin resistance acting on multiple levels of metabolism. PLoS One 2011;6(6):e21187.

24. Teodoro GF, Vianna D, Torres-Leal FL, Pantaleão LC, MatosNeto EM, Donato J. Leucine is essential for attenuating fetal growth caused by a protein-restricted diet in rats. J Nutr 2012;142(5):924-30.

25. Vianna D, Resende G.F, Torres-Leal FL, Pantaleão LC, Donato J, Tirapegui J. Long-term leucine supplementation reduces fat mass gain without changing body protein status of aging rats. Nutrition 2012; 28(2):182-9.

26. Zhang Y, Guo K, LeBlanc RE, Loh D, Schwartz GJ, Yu YH. Increasing dietary leucine intake reduces diet-induced obesity and improves glucose and cholesterol metabolism in mice via multimechanisms. Diabetes 2009;56(6):1647-54.

27. Torres-Leal FL, Vianna D, Teodoro GFR, Capitani MD, Tirapegui J. Aspectos atuais do efeito da leucina sobre o controle glicêmico e a resistência à insulina. J Braz Soc Food Nutr 2010;35(2):131-43.

28. O'Connell TM. The complex role of branchel chain amino acids in diabetes and cancer. Metabolites 2013;(3):931-45.

29. Balage M, Dupont J, Mothe-Satney I, Tesseraud S, Mosoni L, Dardevet D. Leucine supplementation in rats induced a delay in muscle IR/PI3K signaling pathway associated with overall impaired glucose tolerance. J Nutr Biochem 2011;22(3):21926.

30. Haraguchi FK, Silva ME, Neves LX, Santos RC, Pedrosa ML. Whey protein precludes lipid and protein oxidation and improves body weight gain in resistance-exercised rats. Eur J Nutr 2011;50(5):331-9.

31. Wilborn CD, Taylor LW, Outlaw J, Williams L, Campbell B, Foster CA, et al. The Effects of Pre and Pos-Exercise Whey vs. Casein Protein Consumption on Boby. J Sports Sci Med 2013;12(1):74-9.

32. McGregor RA, Poppitt SD. Milk protein for improved metabolic health: a review of the evidence. Nutr Metab 2013;10:46.

33. Zanchi NE, Ferreira LG, Siqueira Filho MA, Felitti V, Nicastro H, Bueno CB, et al. Dose and latenccy effects of leucine supplementation in modulating glucose homeostasis: opposite effects in healthy and glucocorticoid-induced insulin-resistance states. Nutrients 2012;(4):1851-61.

34. Freudenberg A, Petzke KJ, Klaus S. Dietary 1-leucine and 1-alanine supplementation have similar acute effects in the prevention of high-fat diet-induced obesity. Amino Acids 2013(44):519-28.

35. Xin Tong MS, Wei Li MS, Jia-Ying Xu, Shurfen Han, Li-Qiang Qin. Effects of whey protein and leucine supplementation on insulin resistance in non-obese insulin-resistant model rats. Nutrition 2014;30(9):1076-80.

36. Hamad EM, Taha SH, AbouDawood AG, Sitohy MZ,
Abdel-Hamid M. Protective effect of whey proteins against nonalcoholic fatty liver in rats. Lip Health Dis 2011;10-57.

37. Toedebusch RG, Childs TE, Hamilton SR, Crowley JR, Booth FW, Roberts MD. Postprandial leucine and insulin responses and toxicological effects of a novel whey protein hydrolysatebased supplement in rats. J Int Soc Sports Nutr 2012;9:24.

38. Frestedt JL, Zenk JL, Kuskowski MA, Ward LS, Bastian ED. A whey-protein supplement increases fat loss and spares lean muscle in obese subjects: a randomized human clinical study. Nutr Metab 2008;5:8.

39. Pal S, Ellis V. The chronic effects of whey proteins on blood pressure, vascular function, and inflammatory markers in overweight individuals. Obesity 2010;18:1354-9.

40. Solah VA, Kerr DA, Adikara CD, Meng X, Binns CW, Zhu K, Devine A, Prince RL. Differences in satiety effects of alginateand whey protein-based foods. Appetite 2010;54:485-91.

41. Veldhorst MA, Nieuwenhuizen AG, Hochstenbach-Waelen A, Van-Vught AJ, Westerterp KR. Dose-dependent satiating effect of whey relative to casein or soy. Physiol Behav 2009;96:675-82.

42. Foltz M, Ansems P, Schwarz J, Tasker MC, Lourbakos A, Gerhardt CC. Protein hydrolysates induce CCK release from enteroendocrine cells and act as partial agonists of the CCK1 receptor. J Agric Food Chem 2008;56:837-43.

43. Li X, Wang X, Liu R, Guo H, Hao L, Yao P, et al. Chronic leucine supplementation increases body weight and insulin sensitivy in rats on high-fat diet likely by promoting insulin signaling in insulin-target tissues. Mol Nutr Food Res 2013;57:1067-79.

44. Pereira MG, Baptista IL, Carlassara EOC, Moriscot AS, Aoki MS, Miyabara EH. Leucine supplementation improves skeletel muscle regeneration after cryolesio in rats. Plos One 2014; 9(1):e85283.

45. Noatsch A, Petzke KJ, Millrose MK, KlausS. Body weight and energy homeostasis was not affected in C57BL/6 mice fed hight whey protein or leucine-supplemented low-fat diets. Eur J Nutr 2011;50(6):479-88.

46. Frank H, Graf J, Amann-Gassner U, Bratke R, Daniel $\mathrm{H}$, Heemann $\mathrm{U}$, et al. Effect of short-term high-protein comparedwith normal-protein diets on renal hemodynamics andassociatedvariables in healthy young men. Am J Clin Nutr 2009;90:1509-16.

47. Haldis H. Urinary loss of tricarboxylic acid cycle intermediates as revealed by metabolomics studies: an underlying mechanism to reduce lipid accretion by whey protein ingestion? J Proteome Res 2014;13(5):2560-70.

48. Mortensen LS, Holmer-Jensen J, Hartvigsen ML, Jensen VK, Astrup A, De Vrese M, et al. Effects of different fractions of whey protein on postprandial lipid and hormone responses in type 2 diabetes. Eur J ClinNutr 2012;66(7):799-805.

49. Torres-Leal FL, Fonseca-Alaniz MH, Teodoro GF, de Capitani MD, Vianna D, Pantaleão LC, et al. Leucine supplementations improves adiponectin and total choclesterol concentrations despite the lack of changes in adiposity or glucose homeostasis in rats previously exposed to a high-fat diet. Nutr Metab 2011;8:62. doi: 10.1186/1743-7075-8-62.

50. Juraschek SP, Appel LJ, Anderson CA, Miller ER. Effect of a high-protein diet on kidney function in healthy adults: results from the ommiheart trial. Am J Kidney Dis 2013; 61(4):54754. doi: 10.1053/j.ajkd.2012.10.017.

51. Lollo PCB. Proteínas do soro de leite e sua suplementação com L-Leucina: influência, nos parâmetros bioquímicos, moleculares e composição corporal, de ratos wistar 
exercitados. Tese. [Doutorado em Alimentos e Nutrição] - Universidade Estadual de Campinas, Faculdade de Engenharia de Alimentos; 2012.

52. Nilsson M, Holst JJ, Björck I. M. Metabolic effects of amino acid mixtures and whey protein in healthy subjects: studies using glucose-equivalent drinks. Am J Clin Nut 2007;85(4):996-1004.
53. Haraguchi FK, Pedrosa ML, De Paula H, Santos RC, Silva ME. Influência das proteínas do soro sobre enzimas hepáticas, perfil lpídico e formação óssea de ratos hipercolesterolêmicos. Rev Nutr 2009;22(4):517-25.

54. Adams SH. Emerging perspectives on essential amino acid metabolism in obesity and the insulin-resistant state. Adv Nutr 2011;2(6):445-56. 